\title{
Management of MR Imaging in Abnormal Uterine Bleeding
}

Mohammad Tharwat Mahmoud Solyman ${ }^{1}$,Abdou Saeed Ait-Allah ${ }^{2}$, Mohammad Alaa

Alsaid Mohammad', Mohammad Hasan Alam-Edeen', Yasser Abdel-kareem Amin ${ }^{1}$

${ }^{1}$ Department of Radiodiagnosis, ${ }^{2}$ Department of Obstetrics and Gynecology, Faculty of Medicine, Sohag University

*Corresponding author: Yasser Abdel-kareem Amin, Mobile: (+20) 01006875117, E-Mail: yasserrad476@gmail.com

\begin{abstract}
Background: Abnormal uterine bleeding (AUB) is a common condition that leads to increased health care costs and decreased quality of life. A systematic approach to AUB evaluation can simplify management and enhance women's well-being.

Objective: Management of MRI in women with AUB to detect any organic cause not detected with transvaginal ultrasonographic examination and if MRI add any advantage more than transvaginal ultrasound.

Patients and methods: Fifty women with abnormal uterine bleeding were referred from the outpatient clinic and inpatients of OB/GYN Department at Sohag University Hospital was subject for this study.

Results: MRI results in the diagnosis of fibroid had a sensitivity and specificity of $100 \%$ and the 2D TVS had a sensitivity of $80 \%$ and specificity $100 \%$. The falsely positive MRI was focal type adenomyosis miss diagnosed as interstitial fibroid. The sensitivity of the MRI for the adenomyosis in our results was $100 \%$ with specificity was $95 \%$. Our results of adenomyosis using 2D transvaginal ultrasound had sensitivity $80 \%$ and specificity $97.5 \%$. Our results using MRI had a sensitivity of $100 \%$ in endometrial polyp detection with specificity $90.47 \%$. TVS had a sensitivity of $50 \%$ with specificity $100 \%$.
\end{abstract}

Conclusion: Management of MRI in abnormal uterine bleeding as equal as that of TVS but still TVS has the upper hand as the first imaging choice, real time imaging. patients also preferred TVS than MRI.

Keywords: Management of MR Imaging, Abnormal Uterine Bleeding, TVUS, FIGO, Quality of Life

\section{INTRODUCTION}

AUB affects women of all ages and constitutes a major proportion of outpatient referrals to the department of gynecology. The lifetime prevalence of AUB in women is $30 \%$. AUB can have a significant impact on women's quality of life. Most women present with HMB that affects their medical, social, economic and psychological well-being ${ }^{(\mathbf{1})}$.

Abnormal uterine bleeding (AUB), a frequent reason for outpatient and emergency department visits in reproductive-aged women, may substantially affect quality of life. Evaluation and management of AUB incurs high health care costs, especially when including the common use of hysterectomy ${ }^{(2)}$.

Fortunately, AUB can often be managed with safe, effective, and noninvasive medical treatments focused on the source of bleeding. Hormonal contraceptives remain a common medical therapy, and the 52-mg levonorgestrel intrauterine system (LNG IUS) is increasingly used to effectively manage troublesome bleeding before a surgical approach. The etiology in reproductive-aged women is almost always benign; however, evaluation and research into AUB was limited by the inconsistent use of terminology and documentation of etiology. The International Federation of Gynecology and Obstetrics (FIGO) Systems 1 and 2 were created to provide clear terminology and nomenclature to globally facilitate the accurate diagnostic and effective treatment approaches to AUB ${ }^{(3)}$.

The International Federation of Gynecology and Obstetrics (FIGO) has approved a new classification system (PALM-COEIN) for causes of abnormal uterine bleeding (AUB) in non-gravid women of reproductive age. The classification system is stratified into nine basic categories that are arranged according to the acronym PALM-COEIN: Polyp, Adenomyosis, Leiomyoma, Malignancy and hyperplasia, Coagulopathy, Ovulatory Disorders, Endometrial, Iatrogenic, and Not Classified ${ }^{(4)}$.

Diffusion-weighted MRI (DWI) is a nonenhanced imaging technique that facilitates the display of tissue characteristics based on the difference in diffusion motion of water molecules. Several recent studies have reported DWI to be useful to detect and differentiate endometrial cancer from normal endometrium or a benign lesion ${ }^{(5)}$.

Recently, the use of DWI with MRI for gynecological malignancies has mainly concentrated not only on detection of disease, but also staging and differentiating benign from malignant tumors ${ }^{(6)}$.

Adenomyosis is defined as the presence of ectopic endometrial glands and stroma within the myometrium. It is a disease of the inner myometrium and results from infiltration of the basal endometrium into the underlying myometrium. Transvaginal ultrasonography (TVUS) and magnetic resonance imaging (MRI) are the main radiologic tools for this condition. A thickness of the junctional zone of at least $12 \mathrm{~mm}$ is the most frequent MRI criterion in establishing the presence of adenomyosis. Adenomyosis can appear as a diffuse or focal form. Adenomyosis is often associated with hormonedependent lesions such as leiomyoma ${ }^{(7)}$. 


\section{AIM OF THE WORK}

Management of MRI in women with AUB to detect any organic cause not detected with transvaginal ultrasonographic examination and if MRI add any advantage more than transvaginal ultrasound.

\section{Patient and methods:}

Inclusion criteria:

Fifty women with abnormal uterine bleeding who referred from the outpatient clinic and inpatients of OB/GYN Department at Sohag University Hospital were subjected for this study.

Exclusion criteria;

Patients with systemic diseases (liver, thyroid ......

- Patients with positive pregnancy test

- Patients on oral anticoagulants/ antithrombotic therapy

- Patients with hematological disorders

The included patients were undergoing;

- Clinical examination.

- Laboratory investigations (blood picture, renal and hepatic functions)

- Transvaginal ultrasound.

- Pelvic MRI:

All the data of history and clinical examination were obtained from the patient files of Obstetrics/Gynecology department. Demographic characteristics (age, residency, occupation and education), medical history, history of abdominal or pelvic surgery, and current medical conditions/medications (diabetes and hypertension), including a history of cancer (history of breast cancer). Information regarding menstrual patterns, reproductive history, history of contraceptive and hormone use, and menopausal status were obtained from the patient sheet.

Ethical consideration and Written informed consent:

An approval of the study was obtained from Sohag University academic and ethical committee and a written informed consent is obtained from all patients.

Methods: -

2D transvaginal ultrasound evaluation of the uterus in longitudinal and transverse views for evaluation of myometrium and endometrium.

The MRI sequences includes T1 (axial, coronal and sagittal) T1 FAT SAT (fat saturation) in axial and sagittal planes and $\mathrm{T} 1$ with gadolinium when indicates.

High resolution T2 weighted imaging of the pelvis in sagittal, axial oblique (perpendicular) (short axis T2 weighted images) and coronal oblique (parallel) to the uterine cavity (long axis T2 weighted images).
MRI diffusion; Diffusion with $\mathrm{b}$ factors of $0-100$ and $800 / \mathrm{mm} 2$. The region of interest was defined within the tumor on T2-weighted

Exclusion criteria: Positive pregnancy test patient and systemic disease with bleeding tendency.

\section{Statistical analysis:}

Recorded data were analyzed using the statistical package for social sciences, version 20.0 (SPSS Inc., Chicago, Illinois, USA). Quantitative data were expressed as mean \pm standard deviation (SD). Qualitative data were expressed as frequency and percentage.

\section{The following tests were done:}

- Independent-samples t-test of significance was used when comparing between two means.

- Chi-square $\left(\mathrm{x}^{2}\right)$ test of significance was used in order to compare proportions between two qualitative parameters.

- The confidence interval was set to $95 \%$ and the margin of error accepted was set to $5 \%$. The p-value was considered significant as the following:

- $\quad$ Probability (P-value)

- P-value $<0.05$ was considered significant.

- P-value <0.001 was considered as highly significant.

- P-value >0.05 was considered insignificant.

\section{RESULTS}

Table 1: Characteristics of studied population.

\begin{tabular}{|l|l|}
\hline Variable & Summery statistics \\
\hline Age & $\begin{array}{l}\text { Mean } \pm \text { S.D 43.72 } \pm 11.72 \\
\text { Median (range) 43 (23- } \\
\text { 75) }\end{array}$ \\
\hline Parity & $\begin{array}{l}\text { Nulliparous 8 cases } \\
(16 \%) \\
\text { Multiparous 42 cases } \\
(84 \%)\end{array}$ \\
\hline Residency & $\begin{array}{l}\text { Rural 40 (80\%) } \\
\text { Urban 10 (20\%) }\end{array}$ \\
\hline Occupation & $\begin{array}{l}\text { Employee 7 (14\%) } \\
\text { Housewife 43 (86\%) }\end{array}$ \\
\hline Menstrual status & $\begin{array}{l}\text { Premenopausal } 27 \\
(54.00 \%) \\
\text { Perimenopausal 17 } \\
(34.00 \%) \\
\text { Postmenopausal 6 } \\
(\mathbf{1 2 . 0 0 \% )}\end{array}$ \\
\hline
\end{tabular}

This study included 50 women who had uterine causes of abnormal uterine bleeding. Their age ranged from 23-75years with median 43years and mean \pm SD (43.72 \pm 11.72$)$.- Twenty-seven cases (54\%) were premenopausal while the perimenopausal women were-17cases (34\%) and the postmenopausal cases were $6(12 \%)$. 
Table 2: MRI diagnosis of studied population:

\begin{tabular}{|l|l|}
\hline MRI diagnosis & Number (\%) \\
\hline Normal & $\mathbf{1 9}(\mathbf{3 8 \%})$ \\
\hline Adenomyosis & $\mathbf{5 ( 1 0 . 0 0 \% )}$ \\
\hline Fibroid & $\mathbf{7 ( 1 4 . 0 0 \% )}$ \\
\hline Polyp & $\mathbf{3 ( 6 . 0 0 \% )}$ \\
\hline Fibroid \& adenomyosis & $\mathbf{3 ( 6 . 0 0 \% )}$ \\
\hline Hyperplasia & $\mathbf{3 ( 6 0 0 \% )}$ \\
\hline Hyperplasia and polyp & $\mathbf{4 ( 8 \% )}$ \\
\hline Adenomyosis \&Polyp & $\mathbf{4 ( 8 . 0 0 \% )}$ \\
\hline Fibroid\&polyp & $\mathbf{1 ( 2 \% )}$ \\
\hline Endometrial carcinoma & $\mathbf{1 ( 2 \% )}$ \\
\hline
\end{tabular}

MRI findings showed that, 19 cases were normal, and five cases had adenomyosis. Seven cases had multiple interstitial fibroid with variable size $(1 \mathrm{~cm}$ to $3 \mathrm{~cm}$ ) and one case had in addition submucosal fibroid $14 \mathrm{~mm}$ while three cases had polyps' size (2$4 \mathrm{~cm})$. Also, three cases had combined fibroid as well as adenomyosis. Three cases had endometrial hyperplasia and 4 cases had hyperplasia and polyps. Four cases had combined findings of adenomyosis and polyps. Single patient had polyp in addition to fibroid while endometrial carcinoma was seen in a single patient.

Table 3: Transvaginal ultrasound diagnosis of studied population.

\begin{tabular}{|l|l|}
\hline $\begin{array}{c}\text { Transvaginal ultrasound } \\
\text { diagnosis }\end{array}$ & \multicolumn{1}{|c|}{ Number (\%) TVS } \\
\hline Normal & $21(42 \%)$ \\
\hline Fibroid & $\mathbf{8 ( 1 6 . 0 0 \% )}$ \\
\hline Adenomyosis & $\mathbf{8 ( 1 6 . 0 0 \% )}$ \\
\hline Hyperplasia & $\mathbf{7 ( 1 4 . 0 0 \% )}$ \\
\hline polyp & $\mathbf{4 ( 8 0 0 \% )}$ \\
\hline Atrophic & $1(2 \%)$ \\
\hline Endometrial carcinoma & $1(2 \%)$ \\
\hline
\end{tabular}

In our study the transvaginal ultrasound examination diagnosed 21 cases as normal, eight cases had fibroid, eight cases had adenomyosis, seven cases had hyperplasia and four cases had polyp while one had case atrophic endometrium and one case endometrial carcinoma.

Table 4: Histopathological diagnosis of studied population

\begin{tabular}{|l|l|}
\hline \multicolumn{1}{|c|}{ Histopathological diagnosis } & \multicolumn{1}{|c|}{ Number $(\%)$} \\
\hline $\begin{array}{l}\text { Proliferative type of } \\
\text { endometrium }\end{array}$ & $22(\mathbf{4 4 \%})$ \\
\hline Adenomyosis & $\mathbf{7 ( 1 4 . 0 0 \% )}$ \\
\hline Fibroid & $\mathbf{7 ( 1 4 . 0 0 \% )}$ \\
\hline Polyp & $\mathbf{4 ( 8 . 0 0 \% )}$ \\
\hline Fibroid \& adenomyosis & $\mathbf{2 ( 4 . 0 0 \% )}$ \\
\hline Hyperplasia & $\mathbf{2 ( 4 . 0 0 \% )}$ \\
\hline Polyp \& hyperplasia & $\mathbf{2 ( 4 . 0 0 \% )}$ \\
\hline Adenomyosis \&Polyp & $\mathbf{1}(\mathbf{2 . 0 0 \% )}$ \\
\hline Fibroid\&polyp & $\mathbf{1 ( 2 . 0 0 \% )}$ \\
\hline Atrophic endometrium & $\mathbf{1 ( 2 . 0 0 \% )}$ \\
\hline Carcinoma & $\mathbf{1}(\mathbf{2 . 0 0 \% )}$ \\
\hline
\end{tabular}

The histopathological results were obtained from all patients in the study after surgical biopsy from 10 cases, endometrial biopsy from 5 cases and D\&C from 35 cases. Most of patients had endometrial proliferative disease that constituted $44 \%$ of study population $(n=22)$. Other piopsies revealed adenomyosis, fibroid \& polyps and endometrial hyperplasia with or without polyp and atrophic endometrium. Only, one case was diagnosed as endometrial carcinoma.

Table 5: Accuracy rates of MRI \& TVS for diagnoses of fibroid:

\begin{tabular}{|c|c|c|c|c|c|}
\hline \multirow[t]{2}{*}{ Study } & \multirow[t]{2}{*}{ Finding } & \multicolumn{2}{|c|}{ Pathological finding } & \multirow{2}{*}{\multicolumn{2}{|c|}{$\begin{array}{c}\text { Diagnostic potentia } \\
(\%)\end{array}$}} \\
\hline & & Abnormal & Normal & & \\
\hline \multirow{5}{*}{ MRI } & Abnormal & 10 & 1 & Sensitivity & 100 \\
\hline & & & & Specificity & 100 \\
\hline & Normal & 0 & 39 & PPV & 90.90 \\
\hline & & & & NPV & 100 \\
\hline & & & & Accuracy & 98 \\
\hline \multirow{5}{*}{ TVS } & Abnormal & 8 & 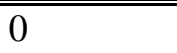 & Sensitivity & 80 \\
\hline & & & & Specificity & 100 \\
\hline & Normal & 2 & 40 & PPV & 100 \\
\hline & & & & NPV & 95.23 \\
\hline & & & & Accuracy & 96 \\
\hline
\end{tabular}

MRI results in the diagnosis of fibroid had a sensitivity and specificity of $100 \%$ and the 2D TVS had a sensitivity of $80 \%$ and specificity $100 \%$. The falsely positive MRI was focal type adenomyosis miss diagnosed as interstitial fibroid. The TVS missed the diagnosis of submucosal fibroid case and miss an interstitial fibroid with the diffuse adenomyosis the size was $12 \mathrm{~mm}$. 
Table 6: Accuracy rates of MRI \& TVS for diagnoses of adenomyosis:

\begin{tabular}{|c|c|c|c|c|c|}
\hline$\overline{\text { Study }}$ & Finding & \multicolumn{2}{|c|}{\begin{tabular}{|l|l} 
Pathological finding \\
\end{tabular}} & \multicolumn{2}{|c|}{\begin{tabular}{|l} 
Diagnostic potential \\
$(\%)$
\end{tabular}} \\
\hline MRI & $\begin{array}{l}\text { Abnormal } \\
\text { Normal }\end{array}$ & 10 & $\begin{array}{l}2 \\
38\end{array}$ & $\begin{array}{l}\text { Sensitivity } \\
\text { Specificity } \\
\text { PPV } \\
\text { NPV } \\
\text { Accuracy }\end{array}$ & $\begin{array}{l}100 \\
95 \\
83.33 \\
100 \\
96\end{array}$ \\
\hline TVS & $\begin{array}{l}\text { Abnormal } \\
\text { Normal }\end{array}$ & 8 & $\begin{array}{l}1 \\
39\end{array}$ & $\begin{array}{l}\text { Sensitivity } \\
\text { Specificity } \\
\text { PPV } \\
\text { NPV } \\
\text { Accuracy }\end{array}$ & $\begin{array}{l}80 \\
97.5 \\
88.88 \\
95.12 \\
94\end{array}$ \\
\hline
\end{tabular}

The sensitivity of the MRI for the adenomyosis in our results was $100 \%$ with specificity was $95 \%$. Our results of adenomyosis using 2D transvaginal ultrasound had sensitivity $80 \%$ and specificity $97.5 \%$.

Table 7: Accuracy rates of MRI \& TVS for diagnoses of polyp:

\begin{tabular}{|ll||ll||ll||}
\hline Study & Finding & \multicolumn{2}{|l|}{ Pathological finding } & Diagnostic potential \\
& & Abnormal & Normal & (\%) \\
\hline \hline \multirow{2}{*}{ MRI } & Abnormal & 8 & 4 & Sensitivity & 100 \\
& & & & Specificity & 90.47 \\
& Normal & 0 & 38 & PPV & 66.66 \\
& & & & NPV & 100 \\
& & & & Accuracy & 92 \\
\hline \hline \multirow{2}{*}{ TVS } & Abnormal & 4 & 0 & Sensitivity & 50 \\
& & & & Specificity & 100 \\
& Normal & 4 & 42 & PPV & 100 \\
& & & & NPV & 91.30 \\
& & & & Accuracy & 92 \\
\hline
\end{tabular}

Our results using MRI had a sensitivity of $100 \%$ in endometrial polyp detection with specificity $90.47 \%$. TVS had a sensitivity of $50 \%$ with specificity $100 \%$.

Table 8: Accuracy rates of MRI \& TVS for diagnoses of hyperplasia:

\begin{tabular}{|c|c|c|c|c|c|}
\hline Study & Finding & \multicolumn{2}{|c|}{\begin{tabular}{|l|l} 
Pathological finding \\
\end{tabular}} & \multicolumn{2}{|c|}{\begin{tabular}{|l|} 
Diagnostic potential \\
$(\%)$
\end{tabular}} \\
\hline MRI & $\begin{array}{l}\text { Abnormal } \\
\text { Normal }\end{array}$ & $\begin{array}{l}4 \\
0\end{array}$ & $\begin{array}{l}3 \\
43\end{array}$ & $\begin{array}{l}\text { Sensitivity } \\
\text { Specificity } \\
\text { PPV } \\
\text { NPV } \\
\text { Accuracy }\end{array}$ & $\begin{array}{l}100 \\
93.47 \\
57.14 \\
100 \\
96\end{array}$ \\
\hline TVS & $\begin{array}{l}\text { Abnormal } \\
\text { Normal }\end{array}$ & $\begin{array}{l}3 \\
1\end{array}$ & $\begin{array}{l}4 \\
42\end{array}$ & $\begin{array}{l}\text { Sensitivity } \\
\text { Specificity } \\
\text { PPV } \\
\text { NPV } \\
\text { Accuracy }\end{array}$ & $\begin{array}{l}75 \\
91.30 \\
42.85 \\
97.67 \\
90\end{array}$ \\
\hline
\end{tabular}

In the diagnosis of endometrial hyperplasia MRI had a sensitivity of $100 \%$ and specificity $93.47 \%$ and the $2 \mathrm{D}$ TVS had a sensitivity $75 \%$ and specificity $91.30 \%$. 
Table 9: Accuracy rates of MRI \& TVS for diagnoses of endometrial carcinoma (one case):

\begin{tabular}{|c|c|c|c|c|c|}
\hline Study & Finding & \multicolumn{2}{|c|}{ Pathological finding } & \multicolumn{2}{|c|}{$\begin{array}{l}\text { Diagnostic potential } \\
(\%)\end{array}$} \\
\hline MRI & $\begin{array}{l}\text { Abnormal } \\
\text { Normal }\end{array}$ & $\begin{array}{l}1 \\
0\end{array}$ & $\begin{array}{l}0 \\
49\end{array}$ & $\begin{array}{l}\text { Sensitivity } \\
\text { Specificity } \\
\text { PPV } \\
\text { NPP } \\
\text { Accuracy }\end{array}$ & $\begin{array}{l}100 \\
100 \\
100 \\
100 \\
100\end{array}$ \\
\hline TVS & $\begin{array}{l}\text { Abnormal } \\
\text { Normal }\end{array}$ & $\begin{array}{l}1 \\
0\end{array}$ & $\begin{array}{l}0 \\
49\end{array}$ & $\begin{array}{l}\text { Sensitivity } \\
\text { Specificity } \\
\text { PPV } \\
\text { NPP } \\
\text { Accuracy }\end{array}$ & $\begin{array}{l}100 \\
100 \\
100 \\
100 \\
100\end{array}$ \\
\hline
\end{tabular}

The results of MRI in endometrial carcinoma gave sensitivity and specificity like the results of TVS (100\% sensitivity and $100 \%$ specificity) with accuracy $100 \%$.

\section{DISCUSSION}

Endometrial carcinoma is the most common gynecologic malignancy. It predominantly affects postmenopausal women. Clinically, patients present with abnormal uterine bleeding. Endometrial carcinoma is usually characterized by endometrial thickening or an endometrial mass. Some benign endometrial lesions such as endometrial hyperplasia and endometrial polyps may also cause uterine bleeding and endometrial thickening or a focal mass. Therefore, those pathologies should be discriminated to navigate the treatment process. Therefore, biopsy is recommended as a second-step diagnostic method when endometrial thickness exceeds $4 \mathrm{~mm}$. However, endometrial biopsy or dilatation and curettage (D\&C) may not be possible in postmenopausal patients due to endometrial atrophy, endometrial adhesions, or the requirement of general anesthesia. Magnetic resonance imaging (MRI), with its superior soft tissue contrast and multiplanar imaging capability, plays a key role in the evaluation of suspected endometrial pathology. Diffusion-weighted MRI (DWI) is a nonenhanced imaging technique that facilitates the display of tissue characteristics based on the difference in diffusion motion of water molecules. Several recent studies have reported DWI to be useful to detect and differentiate endometrial cancer from normal endometrium or a benign lesion (5).

In our study the most common cause of abnormal uterine bleeding is non-organic cause (46\%) followed by adenomyosis (14\%), fibroid (14\%), polyp (8\%), hyperplasia (4\%), endometrial carcinoma (2\%), fibroid \& adenomyosis (4\%), polyp\& hyperplasia(4\%), adenomyosis\& polyp (2\%) and fibroid \&polyp (2\%) . Our results agreed with Soleymani et al. (8) who concluded that the proliferative endometrium and secretory endometrium were the most common histopathological observations in AUB patients.

Also, our results agreed with Singh and Ramana ${ }^{(9)}$ they also concluded that the commonest histopathological pattern in abnormal uterine bleeding was normal physiological phases of menstrual cycle.

In our study; abnormal uterine bleeding was more common in multipara. This agreed with Singh and Ramana ${ }^{(9)}$, they concluded that the incidence of AUB was noticed to be increasing with parity.

Our study revealed that endometrial atrophy seen in one case $2 \%$ which agreed with Singh and Ramana ${ }^{(9)}$, where endometrial atrophy accounted $3 \%$ of cases in their study.

Our study revealed MRI sensitivity for uterine pathology $100 \%$, specificity $82.60 \%$. This agreed with Yadav (10) who concluded that overall sensitivity for detection of lesions by MRI reached $100 \%$ while specificity was $98.41 \%$. Our results disagreed with Dueholm et al. ${ }^{(11)}$ who found the MRI sensitivity was $76 \%$ and specificity was $92 \%$ and disagree with Ahmad $\boldsymbol{e t}$ al. ${ }^{(12)}$ who found the sensitivity was $78.75 \%$ and specificity was $63.64 \%$.

Our study revealed a sensitivity of TVS was $100 \%$ and specificity was $95.56 \%$ in detecting uterine pathology which agreed with Babacan $\boldsymbol{e t}$ al. (13).

\section{The current study for premenopausal women patients:}

MRI sensitivity was $100 \%$, specificity $81.25 \%$, PPV $78.57 \%$, NPV $100 \%$ and accuracy $88.8 \%$. The present results disagreed with Dueholm et al. (11) who concluded that the overall sensitivity MRI was $76 \%$, specificity $92 \%$, PPV $86 \%$ and NPV $86 \%$. This can be explained by, his population number was one hundred and six consecutive premenopausal women who underwent hysterectomy for benign diseases. 
Also, the study had evaluated the uterine cavity and disagreed with Ahmad et al. ${ }^{(12)}$ in which MRI sensitivity reached $71.43 \%$, specificity $55.56 \%$, PPV 78.95\%, NPV $45.45 \%$ and accuracy $66.67 \%$. This discrepancy can be explained by low sensitivity of the MRI was done for all patients using GE (signa contour) $0.3 \mathrm{~T}$ also that study evaluated the uterine cavity lesions only.

Our TVS sensitivity for uterine pathology in premenopausal women was $100 \%$, specificity $87.5 \%$, PPV $84.61 \%$, NPV $100 \%$ and accuracy $92.59 \%$ this agreed with sensitivity of Niharika ${ }^{(14)}$ in his study TVS sensitivity was $100 \%$ and specificity was $87 \%$ in identifying pathology. Also, our study results agreed with Yela et al. ${ }^{(18)}$ who concluded that in the reproductive-age group, TVS had a sensitivity of $96.0 \%$ and accuracy of $91.5 \%$. Our study disagreed with a study done by Aslam $\boldsymbol{e t}$ al. ${ }^{(\mathbf{1 5})}$ in which TVS sensitivity was $71.43 \%$ and specificity was $67.7 \%$. Aslam et al. ${ }^{(15)}$ study included 100 women with abnormal uterine bleeding were submitted to sequential examination by transvaginal ultrasound eighty-eight women were premenopausal and 12 were postmenopausal women. Our study population was 50 cases $(27$ cases premenopausal, 17 perimenopause and 6 postmenopausal women.

\section{The current study for perimenopause patients:}

MRI sensitivity was $100 \%$, specificity $83.3 \%$, PPV $91.6 \%$, NPV $100 \%$ and accuracy $94.1 \%$ to our knowledge no previous studies specifying the perimenopausal phase by MRI and our study included small number (17 cases) TVS in evaluation of uterine pathology in perimenopausal women had a sensitivity of $83.3 \%$, specificity $100 \%$, PPV $100 \%$, NPV $71.42 \%$ and accuracy $88.23 \%$. Our sensitivity and specificity were agreed with Jain and Chakraborty ${ }^{(16)}$ in their study TVS sensitivity was $76 \%$ and specificity was $94 \%$.

In post menopause women our study revealed sensitivity of TVS was $100 \%$ and specificity was 100\% in detecting uterine pathology. This sensitivity agreed with Alcázar et al. ${ }^{(17)}$ and Yela et al. ${ }^{(18)}$.

In the present work MRI had a sensitivity of $100 \%$ and specificity $100 \%$ for post-menopausal uterine lesions which disagreed with a study done by Ahmad et al. ${ }^{(12)}$ in which the sensitivity was $88.24 \%$ and specificity was $69.23 \%$. This discrepancy can be explained by the number of cases (our case 6 and their cases 30) and the study done for endometrial lesions only, our MRI was 1.5 TESELA and their MRI was 0.3 TESELA.

\section{CONCLUSION}

Management of MRI in abnormal uterine bleeding as equal as that of TVS but still TVS has the upper hand as the first imaging choice, real time imaging. patients also preferred TVS than MRI. MRI diffusion sequence for female pelvis should be added to the routine protocol for female pelvis as regarding the differentiation of benign and malignant endometrial lesions.

\section{REFERENCES}

1. Gath D, Osborn M, Bungay G et al. (1987): Psychiatric disorder and gynaecological symptoms in middle aged women: a community survey. Br Med J (Clin Res Ed), 294(6566):213-218.

2. Showstack J, Lin F, Learman LA et al. (2006): Randomized trial of medical treatment versus hysterectomy for abnormal uterine bleeding: resource use in the Medicine or Surgery (Ms) trial. Am J Obstet Gynecol., 194 (2):332-338.

3. Munro MG (2017): Practical aspects of the two FIGO systems for management of abnormal uterine bleeding in the reproductive years. Best Pract Res Clin Obstet Gynaecol., 40:3-22.

4. Munro MG, Critchley HO, Broder MS et al. (2011): FIGO classification system (PALM- COEIN) for causes of abnormal uterine bleeding in nongravid women of reproductive age. International Journal of Gynecology Obstetrics, 113, 3-13.

5. Çavuşoğlu M, Ciliz DS, Ozsoy A et al. (2016): Diffusion-Weighted Mri of Postmenopausal Women with Vaginal Bleeding and Endometrial Thickening: Differentiation of Benign and Malignant Lesions. Journal of the Belgian Society of Radiology, 100(1):70-5.

6. Keriakos NN, Darwish E (2018): Diffusion Weighted Imaging In Suspicious Uterine Tumors; How Efficient Is It? The Egyptian Journal of Radiology and Nuclear Medicine, 49(3): 838-845.

7. Agostinho L, Cruz R, Guerra A et al. (2016): Adenomyosis and MRI: what you need to know and be aware of 2016 . http://dx.doi.org/10.1594/ecr2016/C-1192

8. Soleymani E, Ziari K, Rahmani $O$ et al. (2014): Histopathological findings of endometrial specimens in abnormal uterine bleeding. Archives of Gynecology and Obstetrics, 289: 845-849.

9. Singh A, Ramana BPV (2016): Study of histopathological pattern of endometrium in abnormal uterine bleeding and its management. https://www.ijrcog.org/ index.php/ijrcog/article/view/599

10. Yadav P (2016): Magnetic resonance imaging in the evaluation of female pelvis. Med J DY Patil Univ., 9: 627-634.

11. Dueholm M, Lundorf E, Hansen ES et al. (2001): Evaluation of the uterine cavity with magnetic resonance imaging, transvaginal sonography, hysterosonographic examination, and diagnostic hysteroscopy. Fertility and Sterility, 76(2): 350-357.

12. Ahmad RA, Sadek SM, Ragheb AS (2015): Evaluation of the uterine cavity by magnetic resonance imaging, three dimensional hysterosonography and diagnostic hysteroscopy in women with pre- and post-menopausal bleeding. Middle East Fertility Society Journal, 20: 70-78. 
13. Babacan A, Gun I, Kizilaslan C et al. (2014): Comparison of transvaginal ultrasonography and hysteroscopy in the diagnosis of uterine pathologies. International Journal of Clinical and Experimental Medicine, 7: 764-769.

14. Niharika SD (2018): Role of Transvaginal Ultrasound and Endometrial Biopsy in Evaluating Abnormal Uterine Bleeding in Reproductive and Perimenopausal Age group. http://jmscr.igmpublication.org/home/index.php/archi ve/157-volume-06-issue-12-december-2018/6361role-of-transvaginal-ultrasound-and-endometrialbiopsy-in-evaluating-abnormal-uterine-bleeding-inreproductive-and-perimenopausal-age-group

15. Aslam M, Ijaz L, Tariq S et al. (2007): Comparison of transvaginal sonography and saline contrast sonohysterography in women with abnormal uterine bleeding: correlation with hysteroscopy and histopathology. International Journal of Health Sciences, 1: 17-24.

16. Jain M, Chakraborty S (2017): Evaluation of abnormal uterine bleeding with transvaginal sonography. International Journal of Reproduction, Contraception, Obstetrics and Gynecology. https://www.ijrcog.org/index.php/ijrcog/article/view/3 $\underline{006}$

17. Alcázar JL, Laparte CJ, Investigation O (1996): Comparative study of transvaginal ultrasonography and hysteroscopy in postmenopausal bleeding. Gynecol Obstet Invest., 41(1):47-9.

18. Yela DA, Pini PH, Benetti-Pinto CL (2018): Comparison of endometrial assessment by transvaginal ultrasonography and hysteroscopy. Int J Gynaecol Obstet., 143(1):32-36. 